\title{
CONCEPÇÕES DE QUALIDADE NOS DOCUMENTOS OFICIAIS SOBRE A EDUCAÇÃO SUPERIOR
}

\author{
CONCEPTS OF QUALITY IN OFFICIAL DOCUMENTS \\ REGARDING HIGHER EDUCATION
}

\author{
CONCEPCIONES DE CALIDAD EN LOS DOCUMENTOS \\ OFICIALES SOBRE LA EDUCACIÓN SUPERIOR
}

\begin{abstract}
José CARlos RotheN ${ }^{1}$
Regilson MACiel Borges ${ }^{2}$

AndReliza Cristina DE SOUZA ${ }^{3}$

Joelma dos Santos Bernardes ${ }^{4}$

Pamela Cristina Botiglieri ${ }^{1}$

Universidade Federal de São Carlos (UFSCar). São Carlos/ SP - Brasil ${ }^{1}$

Universidade Federal de Lavras (UFLA). Lavras/MG - Brasil ${ }^{2}$

Universidade Estadual do Oeste do Paraná (UNIOESTE). Cascavel/PR - Brasil ${ }^{3}$

Universidade Virtual do Estado de São Paulo (UNIVESP). Araraquara/SP - Brasil ${ }^{4}$
\end{abstract}

Resumo Este trabalho resulta de pesquisa que buscou identificar o conceito de qualidade presente nos documentos oficiais e dispositivos legais brasileiros publicados no período de 2003 a 2013. O material foi selecionado no Portal Domínio Público do MEC e no sítio do INEP. No levantamento, foi encontrado um total de 27 documentos. Para a análise dos usos do conceito de qualidade, os documentos foram organizados em cinco categorias temáticas: Qualidade como base para a fundamentação legal; Qualidade tendo como referência a avaliação institucional; Qualidade como relevância social; Quando a qualidade é excelência; Qualidade ancorada em índices e indicadores. A partir disso, o artigo visa contribuir para a elaboração de políticas públicas, ressaltando a importância da definição da concepção de qualidade adotada, acompanhada da devida compreensão acerca de suas possíveis implicações. A análise mostra que não existe uma definição única do que seria qualidade, mas sim uma flutuação no uso do termo que varia de uma visão "formativa-educativa" para uma visão "gerencialista".

Palavras-chave: Qualidade; Avaliação da educação superior; Sistema nacional de aVaLIAÇÃO DA EDUCAÇÃO SUPERIOR. 
Abstract This paper is a result of a research that aimed to identify the concept of quality in official documents and legal provisions published between 2003 and 2013. The material was selected in MEC's website Portal Domínio Público and INEP's website. In this survey, a total of 27 documents were found. In order to analyze the use of concepts of quality, documents were organized in five cathegories: Quality as a basis for legal grounding; Quality that references institutional evaluation; Quality as a social relevance; When quality is excellence; Quality based on rates and indicators. Thus, this article aims to contribute towards elaborating public policies, highliting the importance of defining the concept of quality that is used, with due understanding of its possible implications. Analysis shows that there is no unique definition of what quality is, but a fluctuation in the use of the term, which varies from a "formative-educative" vision to a "managerialist" vision.

Keywords: Quality; EVAluation of higher EDUCATION; National system of EVALUATion of HIGHER EDUCATION.

Resumen Este trabajo es el resultado de una investigación que buscó identificar el concepto de calidad presente en los documentos oficiales y dispositivos legales brasileros publicados en el período que va de 2003 a 2013. El material fue seleccionado en el Portal Domínio Público del MEC y en el sitio web del INEP. En el relevamiento fue encontrado un total de 27 documentos. Para el análisis de los usos del concepto de calidad los documentos fueron organizados en cinco categorías temáticas: Calidad como base para la fundamentación legal; Calidad teniendo como referencia la evaluación institucional; Calidad como relevancia social; Cuando la calidad es excelencia; Calidad basada en índices e indicadores. A partir de esto, el artículo busca contribuir para la elaboración de políticas públicas, resaltando la importancia de la definición de la concepción de calidad adoptada, acompañada de la debida comprensión sobre sus posibles implicaciones. El análisis muestra que no existe una definición única de lo que sería calidad, sino una fluctuación en el uso del término que varía entre una visión "formativa-educativa" y una visión "gerencialista".

Palabras clave: Calidad; Evaluación de la educación superior; Sistema nacional de EVALUACIÓN DE LA EDUCACIÓN SUPERIOR.

\section{INTRODUÇÃo}

Avaliar o ensino, em especial o ensino superior, não é uma novidade que se iniciou com o Sistema Nacional de Avaliação da Educação Superior (SINAES), pois, ao longo das décadas de 1980, 1990 e 2000 ocorreram processos e programas de avaliação que apresentaram diferentes perspectivas, durações e implicações sociopolíticas (BARREYRO; ROTHEN, 2006; 2008). Nesse contexto, o SINAES tem se configurado como uma política de Estado devido a vários fatores, entre os quais o fato de que, nos dias atuais, é difícil prever a ausência de um sistema nacional de avaliação. 
Como política de Estado, o SINAES deveria ter âmbito nacional e envolver todas as IES, públicas ou privadas, grandes ou pequenas, respeitando o pacto federativo (o regime de colaboração entre o sistema federal e os estaduais), bem como a identidade e as especificidades de cada Instituição. O fato de que parte das IES estaduais e municipais não se submeterem ao regime do SINAES não anula seu caráter nacional. Com efeito, o SINAES é praticado em todos os Estados da Federação, estende-se a todo o território brasileiro, operando no sentido de consolidar a Educação Superior nacional (DIAS SOBRINHO, 2010a, p. 208).

O Sistema é composto por três eixos avaliativos que são: a avaliação das instituições de ensino superior, a avaliação dos cursos de graduação e a avaliação do desempenho dos estudantes. Para o desenvolvimento desses eixos, há uma série de instrumentos complementares, entre eles cabe destacar: a Avaliação Externa, a Avaliação Interna (autoavaliação institucional), o Censo da Educação Superior e o Exame Nacional Desempenho de Estudantes (ENADE). E para coordenar e supervisionar o sistema é criada a Comissão Nacional de Avaliação da Educação Superior (CONAES) (BRASIL, 2004a).

No decorrer do desenvolvimento do Sistema, houve instrumentos que foram modificados, aperfeiçoados e outros deixaram de existir. Isso ocorreu porque, à medida que aconteciam os processos avaliativos do Sistema, surgiam demandas de adequação à realidade das Instituições de Ensino Superior (IES), de inquietações da comunidade acadêmica e de entidades representativas da sociedade civil que tinham ligação com o ensino superior. Dias Sobrinho (2010) observa que grande parte dessas mudanças favoreceram o descarte ou o descumprimento de alguns dos princípios e propósitos do SINAES.

Com o aumento das matrículas do ensino superior brasileiro a partir da década de 1960 e sua intensificação nos anos 1990, quando se tem uma forte expansão do setor privado no país (BARREYRO, 2008), a qualidade da oferta da educação superior passou a ser colocada em xeque. Nesse cenário, foram desenvolvidas políticas de avaliação com o objetivo de garantir a qualidade do ensino ofertado, em vista disso, a avaliação da educação superior seria o instrumento que permitiria controlar a qualidade do serviço prestado (TAVARES et al., 2010).

Este texto é produto da pesquisa "Avaliação, Expansão e Qualidade da Educação Superior no século XXI", que integra o Subprojeto 3 da Rede Universitas/Br, desenvolvida pelo "Observatório e pesquisa das políticas de avaliação da educação superior" (POW1/ UFSCar) com o apoio do Conselho Nacional de Desenvolvimento Científico e Tecnológico (CNPq) e do Programa Observatório da Educação (OBEDUC). A pesquisa desse subgrupo tem por objetivo investigar, à luz dos resultados das avaliações de cursos desenvolvidos nas IES no Brasil, a partir da criação do Conceito Preliminar de Curso (CPC), as características dos cursos com as notas mais elevadas (4 e 5), visando à compreensão do que seja "qualidade" na educação superior.

Uma das etapas da referida pesquisa consistiu no levantamento e análise das fontes documentais e dispositivos legais publicados no período de 2003 a 2013 - período que se refere à elaboração, regulamentação, implantação e consolidação do SINAES -, com o 
objetivo de identificar o conceito de qualidade expresso nos documentos oficiais e dispositivos legais que embasaram as políticas de avaliação da educação superior no Brasil.

Diante desse panorama, este artigo apresenta as transformações pelas quais passou o conceito de qualidade à luz dos documentos oficiais que tratam da avaliação da educação superior brasileira, questionando principalmente o significado que o termo adquiriu ao longo da vigência do SINAES.

A fim de se atingirem os objetivos propostos, foi realizada uma pesquisa de caráter documental, por se tratar de um estudo que procura "traçar a evolução histórica [...] [do] problema", conforme ressalta Chizzotti (2006, p. 18).

Para Lüdke e André (1986, p. 38), documentos são quaisquer materiais escritos, nos quais se "incluem desde leis e regulamentos, normas, pareceres, cartas, memorandos, diários pessoais, autobiografias, jornais, revistas, discursos, roteiros de programas de rádio e televisão até livros, estatísticas e arquivos escolares". A análise documental constitui-se, segundo as autoras, numa técnica de grande utilidade para a pesquisa qualitativa, pois possibilita complementar informações já obtidas ou mesmo elucidar novos aspectos de um tema.

As autoras salientam que o primeiro passo para a análise documental é "a caracterização do tipo de documento que será usado ou selecionado" (LÜDKE; ANDRÉ, 1986, p. 40). No caso dessa pesquisa, trata-se de documentos do tipo oficial que incluem Decretos, Diretrizes, Estudos Técnicos, Manuais, Medidas Provisórias, Notas Técnicas, Ofícios, Portarias, Relatórios de Gestão, Resoluções e Resumos Técnicos. Considerou-se como oficial os documentos assinados por órgãos vinculados ao governo federal, como Ministério da Educação (MEC), Instituto Nacional de Estudos e Pesquisas Educacionais Anísio Teixeira (INEP), entre outras Secretarias do MEC. Em outros termos, oficiais são todos os documentos cuja referência bibliográfica obrigatoriamente inicia-se com o termo "Brasil".

Para a obtenção dos dados, foi realizado um levantamento das fontes em dois bancos de dados disponíveis em suporte on-line: o Portal Domínio Público da Secretaria de Educação a Distância (SEED) do MEC e o sítio do INEP. Buscou-se pelos "títulos" dos documentos, com os seguintes descritores: "Educação Superior", "Avaliação", "Qualidade" e "Ensino Superior"; prosseguindo com busca que focalizou o "conteúdo" dos documentos disponíveis no acervo, a partir dos descritores: "Educação Superior", "Avaliação da Educação", "Qualidade da Educação", "Avaliação Educacional", "Qualidade do Ensino" e "Ensino Superior". Nesse levantamento, foi encontrado um total de 122 documentos, sendo que 45 tratavam sobre a temática e 27 destes foram selecionados para o estudo por atenderem diretamente à questão da pesquisa.

Selecionados os documentos, o passo seguinte foi "a análise propriamente dita dos dados", onde tem sido recorrente a "metodologia de análise de conteúdo" (LÜDKE; ANDRÉ, 1986, p. 41). Nesse processo, a unidade de análise foi o texto como um todo, focalizando-se a temática pesquisada. Para tanto, foram confeccionadas fichas de leitura contendo a autoria do texto, o ano de publicação, as palavras-chave, o resumo, a tese do texto, os principais argumentos e como é tratada a questão da qualidade. 
Organizados os dados, procurou-se, em seguida, "detectar temas e temáticas mais frequentes" (LÜDKE; ANDRÉ, 1986, p. 42). Um procedimento que culminou com a construção de algumas categorias que procuram unificar os conteúdos e aspectos recorrentes encontrados nos textos. De acordo com Gomez, Flores e Jiménez (1999, p. 208-209), o desenvolvimento de categorias:

[...] constituye sin duda una importante herramienta en el análisis de datos cualitativos, hace posible clasificar conceptualmente las unidades que son cubiertas por un mismo tópico. Una categoria soporta un significado o tipo de significados [...] Una cuestión importante en la categorización de los datos es estabelecer las categorias a emplear. Estas pueden estar predefinidas por el analista, o por el contrario, pueden surgir a medida que se analizan los datos.

Nesse agrupamento temático por categorias, a intenção foi explicitar as concepções de qualidade presente nos documentos, resultante das inúmeras leituras e releituras do material analisado que, de acordo com Lüdke e André (1986), é um processo imprescindível para a construção de categorias de análise. Por meio desse processo, emergiram cinco categorias temáticas que são: "Qualidade como base para a fundamentação legal"; "Qualidade tendo como referência a avaliação institucional"; "Qualidade como relevância social”; "Quando a qualidade é excelência"; e "Qualidade baseada em índices e indicadores".

A respeito da discussão sobre o conceito de qualidade, compreende-se que este pode ter diferentes conotações, dependendo da abordagem teórica em que ele é pensado. Demo $(1985 ; 2005)$ apresenta duas dessas possibilidades, a qualidade formal, representada pela versatilidade dos meios e do estilo metodológico, processual, científico; e a qualidade política, compreendida pela intensidade democrática e ética frente aos desafios e valores sociais.

Para Freitas (2005), qualidade é produto de um processo de avaliação, que se faz pelas vias de uma negociação, expressa numa qualidade negociada. Segundo Dias Sobrinho (2008), qualidade em educação pressupõe pertinência e relevância social, o que Saul (1990) complementa acrescentando que qualidade da educação superior é um compromisso com a transformação da universidade.

Sendo assim, nota-se que o conceito de qualidade é orientado por diferentes expectativas e que, por isso mesmo, não é um conceito neutro, mas carregado de posicionamento político e ideológico, como ocorre também com a avaliação, sendo "simplista e redutora a idéia de avaliação como um instrumento neutro e capaz de determinar de forma absolutamente objetiva o que é bom ou o que não o é" (DIAS SOBRINHO, 2004, p. 705). Por isso, a avaliação institucional que busca determinada concepção de qualidade nunca é isenta de valores e interesses.

Assim, quando uma avaliação é concebida em termos objetivos, ela é enquadrada em escalas de comparação, se traduzindo então em indicadores como eficiência, eficácia e efetividade. Os indicadores podem ser considerados como um conjunto de instrumentos que permitam a medida da qualidade. Nesse sentido, a tarefa dos indicadores é obter a sintonia entre os aspectos qualitativos e quantitativos que expressem os aspectos objetivos da rea- 
lidade (FERREIRA; TENÓRIO, 2010). Já quando uma avaliação é concebida em termos democráticos, ela é preconizada pela participação da comunidade envolvida e interessada, que irá definir em conjunto quais indicadores serão adotados, com o diferencial negociável dos indicadores. Nessa segunda concepção de avaliação, a formação dos participantes é imprescindível para que a qualidade buscada seja alcançada.

Essas duas concepções de avaliação igualmente sinalizam para a complexidade quando se trata da qualidade em educação, mostrando que o termo pode obter diversos sentidos, podendo significar intensidade da formação humana, juízo valorativo, busca de relevância, negociação ampla e responsável, que apontam para uma concepção de qualidade formativa-educativa, daquilo que Dias Sobrinho (2008a) compreende como sendo um princípio democrático-republicano. Assim como pode também significar, em uma concepção de qualidade gerencialista, a ideia de eficácia, eficiência, efetividade, equidade e satisfação em uma lógica do mercado que modificam as atuações das IES, conforme elucidam Silva Júnior e Sguissardi (2000). Trata-se, portanto, de um conceito que é definido socialmente, sendo influenciado diretamente por "agências e instituições que julgam e definem os padrões de qualidade da educação da educação superior (graduação)" (ROTHEN; BARREYRO, 2009, p. 729).

Este texto está organizado em duas seções. A primeira seção exibe a análise e a interpretação dos dados distribuídos nas categorias temáticas que identificam as concepções de qualidade presentes nos documentos analisados. A segunda seção traz as considerações finais que focalizam as duas principais modificações pelas quais passou o termo qualidade durante o período pesquisado.

\section{CONCEPÇÕES DE QUALIDADE NOS DOCUMENTOS OFICIAIS}

\section{Qualidade como base para a fundamentação legal}

A qualidade do ensino como parte do direito à educação aparece com destaque na Constituição Federal da República Federativa do Brasil, de 1988, na Lei de Diretrizes e Bases da Educação Nacional (LDB), de 1996, e mais recentemente no Plano Nacional de Educação (PNE), de 2014. De acordo com Oliveira (1999, p. 61), a declaração do direito à educação, particularmente detalhada na legislação brasileira no campo educacional, "representa um salto de qualidade à legislação anterior, com maior precisão da redação e detalhamento, introduzindo-se, até mesmo, os instrumentos jurídicos para a sua garantia". É dentro desse contexto que está se entendendo a qualidade como fundamentação legal.

A organização e a implantação de um novo sistema de avaliação, no início da década 2000, é fruto da mudança de governo, que se deu com a eleição, em outubro de 2002, de Luiz Inácio Lula da Silva para a presidência do Brasil. Em seu Programa de Governo é previsto a recuperação da rede pública do ensino com a valorização da qualidade, entendendo que "a educação de qualidade é fator de emancipação e cidadania, contribui para que os jovens se integrem ao mercado de trabalho e evita a fragmentação social que alimenta a violência e o crime organizado" (COLIGAÇÃO LULA PRESIDENTE, 2002, p. 15). Nessa 
perspectiva, seria formulado um novo sistema de avaliação para as instituições de ensino superior. Em 2003, foi criada a Comissão Especial de Avaliação (CEA), "com o objetivo de elaborar uma proposta de avaliação da educação superior em vista das críticas feitas no programa de governo de Lula ao modelo adotado pelo governo anterior" (BARREYRO; ROTHEN, 2014, p. 65).

No documento elaborado pela CEA, "Sistema Nacional de Avaliação da Educação Superior SINAES: Bases para uma Nova Proposta da Educação Superior" (BRASIL, 2003b, p. 17), que propõe o SINAES, se reconhece, por exemplo, que "da Constituição de 1988 às sucessivas Medidas Provisórias, passando pela nova Lei de Diretrizes e Bases da Educação Nacional (LDB), pelo Plano Nacional de Educação (PNE) e por vários Decretos houve indiscutivelmente um progressivo reconhecimento legal da importância da Avaliação associada à ideia de melhoria da qualidade". A Lei destaca ainda a criação do Conselho Nacional de Educação e propõe como uma das atribuições do MEC "zelar pela qualidade do ensino". Esse mesmo documento, com o "Relatório de Gestão 2003 do INEP" (INEP, 2004a), menciona que na nova LDB a necessidade dos processos de avaliação aparece direcionada à qualidade, especificamente seu artigo $9^{\circ}$., inciso VI, referindo-se que é tarefa da União assegurar processo nacional de avaliação com objetivo de definir prioridades e a melhoria da qualidade do ensino.

O documento que propõe o SINAES (BRASIL, 2003b, p. 63) considera que são dois os "mais importantes critérios da qualidade da educação superior", trata-se da "relevância da formação e da produção de conhecimentos para o desenvolvimento do conjunto da população e para o avanço da ciência, e na sua eficácia para fortalecer as preferências éticas e políticas dominantes em um determinado momento histórico". São critérios que combinam o desenvolvimento do país com a formação para a cidadania, correspondendo com aquilo que prevê o artigo 205 da Constituição Federal, ao entender a educação como "pleno desenvolvimento da pessoa, seu preparo para o exercício da cidadania e sua qualificação para o trabalho" (BRASIL, 1988). É salientado ainda que cabe ao Estado supervisionar e regular a educação superior "para efeitos de planejamento e garantia de qualidade do sistema" (BRASIL, 2003b, p. 64). Menciona também algumas diretrizes que se apoiam em pressupostos acadêmicos e políticos, entre as quais destaca a "valorização da missão pública no âmbito local, regional e nacional através de um sistema de avaliação que tenha como principal objetivo a melhoria da qualidade acadêmica e da gestão institucional" (BRASIL, 2003, p. 8), prevendo-se, portanto, a criação de um novo sistema de avaliação da Educação Superior, que veio a se configurar com a implantação do SINAES, em 2004.

"O Relatório de Gestão 2003 do INEP" (INEP, 2004a) menciona que a Constituição Federal de 1988 apresenta a educação de qualidade como um direito fundamental para todos os brasileiros. Semelhante discussão exibe o relatório-síntese "O desafio de uma educação de qualidade para todos: educação no Brasil - 1990-2000" (INEP, 2004b), ao enfatizar o artigo 206, inciso VII da referida Constituição, onde a qualidade aparece como um dos princípios do ensino. 
Nos documentos publicados no início da implantação do SINAES, o termo qualidade está associado à ordem legal que embasa a necessidade da avaliação no contexto educacional. Em outras palavras, a qualidade é um termo sem um significado específico que justifica a realização da avaliação. O "Manual do Enade" (BRASIL, 2009) menciona que o objetivo do SINAES é a melhoria da qualidade da educação, no entanto não explicita o que é qualidade e nem quais os caminhos para essa melhoria da qualidade. Nesse caso, a avaliação realizada pelo SINAES se justifica pela melhoria da qualidade da educação, sendo que o uso da terminologia qualidade vem para sustentar a realização de avaliação em larga escala.

Nessa categoria o termo qualidade está associado à ordem legal que apoia a necessidade da avaliação no contexto educacional brasileiro, contudo, nota-se que os documentos analisados não apresentam explicitamente uma significação específica do que seja qualidade, o termo aparece apenas embasando e legitimando a necessidade da promoção das avaliações como cumprimento à legislação educacional vigente.

\section{Qualidade tendo como referência a avaliação institucional}

A avaliação institucional como instância mediadora da qualidade tem como pressuposto básico a mobilização dos diferentes atores escolares na vida e no destino "das escolas, em direção à negociação de patamares cada vez mais elevados de qualidade" (FREITAS, 2009, p. VI). Nessa via, a avaliação institucional pode ser vista como um "processo sistemático de busca de subsídios para melhoria e aperfeiçoamento da qualidade da instituição" (BELLONI, 1999, p. 40). Assim, para além de serem práticas pontuais e fragmentadas, "a avaliação institucional consiste num empreendimento sistemático que busca compreensão global da Universidade, pelo reconhecimento e pela integração de suas diversas dimensões" (BALZAN; DIAS SOBRINHO, 1995, p. 9).

No relatório-síntese "O desafio de uma educação de qualidade para todos: educação no Brasil - 1990-2000” (INEP, 2004b) são apresentados os desafios para uma educação de qualidade, sendo a qualidade definida a partir das principais metas estabelecidas no Plano Nacional de Educação (PNE) (2001-2010) e dos programas do Plano Plurianual (PPA) do MEC (2004-2007). Com ênfase na qualidade no ensino superior são listados, por exemplo, a ampliação da oferta da educação profissional, tecnológica e da educação superior; o acesso ao ensino de graduação, e pós-graduação, à pesquisa e à extensão; e a oferta de práticas pedagógicas modernas, materiais didáticos atualizados, inovação tecnológica e infraestrutura física e instrumental necessários à aprendizagem. Cabe destacar que, no âmbito de reformulações do SINAES, alguns desses indicadores estarão presentes nos instrumentos de autorização, reconhecimento e renovação na avaliação de instituições e de cursos, conforme prevê o Decreto 5.773 de 2006.

No processo de implantação do SINAES, a CONAES publica as "Diretrizes para a Avaliação das Instituições de Educação Superior" (BRASIL, 2004b) e o "Roteiro de Autoavaliação Institucional” (BRASIL, 2004c). Nas Diretrizes (BRASIL, 2004b, p. 10, grifos do autor) a CONAES aponta algumas diretrizes para a avaliação das instituições, sendo uma delas "comparar o projeto da IES e a sua realidade institucional, ou seja, melhorar a qua- 
lidade acadêmica significa, no contexto de cada instituição, diminuir a distância entre ambos". Compreendendo que a qualidade acadêmica passa, necessariamente, por um processo avaliativo que procura garantir principalmente a relação entre ensino, pesquisa e extensão. Esse Roteiro (BRASIL, 2004c) oferece orientações e sugestões para a avaliação interna do processo de autoavaliação institucional, nele o termo qualidade aparece distribuído nos três núcleos: básico e comum; temas optativos; e documentação, dados e indicadores, que compõem o roteiro de autoavaliação, porém, sem maiores aprofundamentos.

No estudo "Avaliação participativa: perspectivas e desafios" (RISTOFF; JUNIOR ALMEIDA, 2005), há textos que tratam da educação superior, da Comissão Própria de Avaliação (CPA) e do SINAES, além disso, é explicitado que uma das formas de atingir a qualidade educativa na IES é por meio da avaliação interna (autoavaliação institucional), em muitos momentos desenvolvida pela CPA. A autoavaliação possibilita conhecer com maior profundida a realidade institucional e a relevância social da avaliação, isso porque permite que a IES se reconheça e seja reconhecida por meio da divulgação dos resultados alcançados. A partir da autoavaliação institucional desenvolvida pela CPA, é possível apontar os problemas e as deficiências para a melhoria da qualidade pedagógica e para a capacitação profissional, além de verificar e acompanhar se os objetivos propostos, as metas e o planejamento estão de acordo com o pretendido pela gestão institucional.

$\mathrm{Na}$ "Portaria INEP n ${ }^{\circ}$ 31, de 17 de fevereiro de 2005" (BRASIL, 2005a), ao tratar da qualidade da educação superior, expõe-se que cabe à Coordenação Geral de Avaliação Institucional e às Coordenações de Cursos de Graduação implantar e implementar ações e procedimentos no âmbito das suas competências com o objetivo de obter a melhoria da qualidade dos processos e dos produtos relacionados à avaliação. Compete à Coordenação Geral de Avaliação Institucional do MEC e às Coordenações de Cursos de Graduação manter as informações de alunos, de cursos, de infraestrutura, de corpo docente, de técnico-administrativos e entre outros atualizados para que possam ter uma série histórica de ações de melhoria da qualidade da educação superior.

O documento "Avaliação de cursos de graduação: instrumento" (BRASIL, 2006) expõe que para alcançar a qualidade na educação superior a instituição deve possuir uma estrutura acadêmico-administrativa que considere um quadro docente, corpo técnico-administrativo, projeto pedagógico de curso, infraestrutura física, logística e ambiente educacional. No que tange à ação acadêmico-administrativa, exige que tenha múltiplos aspectos para serem contemplados, como organização didático-pedagógica, atividade de prática profissional, entre outros, e também, objetivos a serem alcançados para a melhoria do desempenho do curso, por conseguinte, melhoria da sua qualidade.

Nessa categoria, o termo qualidade aparece atrelado à ideia da avaliação institucional, cujo desenvolvimento se dá por meio da autoavaliação institucional, a cargo da CPA, propiciando a melhoria da qualidade na educação superior, que deve estar em consonância com a responsabilidade social, pois é um juízo de valor que expressa a identidade e a diversidade institucional. Por sua vez, a avaliação de cursos viabilizada pela elaboração de instrumentos que permitem a autorização, o reconhecimento e a renovação de reconhecimento de cursos de graduação. 


\section{Qualidade como relevância social}

A questão da qualidade da educação no Brasil sempre teve uma estreita relação com os propósitos da educação, e esta com as dimensões social, política, econômica e cultural, pois, como afirma Dias Sobrinho (2010, p. 1.225), "a qualidade tem uma irrecusável dimensão social e pública". Ainda, de acordo com esse autor, a qualidade compreende as "transformações da educação superior como aspecto do cenário geral de metamorfoses da sociedade, da economia, do mundo do trabalho e, particularmente, do conhecimento" (DIAS SOBRINHO, 2010b, p. 1.225). Nessa perspectiva, entende-se que a qualidade enquanto relevância social exerce um forte papel na definição geral do termo.

No relatório "O desenvolvimento da educação. Educação de qualidade para todos os jovens: desafios, tendências e prioridades (BRASIL, 2004d)", é mencionado que "a reorganização do sistema de educação superior brasileiro vai exigir a formulação de um novo sistema de avaliação", com objetivo de "identificar as qualidades e os pontos fracos das universidades, a fim de capacitá-las a desempenhar o papel que a sociedade delas espera" (BRASIL, 2004d, p. 77), bem como, é compreendido que "a qualidade acadêmica necessita ser conjugada com relevância social e equidade" (BRASIL, 2004d, p. 76). Enfatiza ainda algumas iniciativas do Governo Federal para elevar a qualidade do ensino, entre as quais se encontram o desenvolvimento de programas nacionais de formação inicial e continuada de professores e a utilização de tecnologias de informação e de comunicação aplicadas à educação presencial e a distância.

Ainda, na perspectiva social, Dourado, Oliveira e Santos (2007), na série documental "A qualidade da educação: conceitos e definições", apontam a dimensão da equidade para a melhoria da qualidade. A qualidade é entendida, nesse contexto, como um fator de promoção da equidade, com destaque para a contribuição das experiências educativas para a promoção da igualdade de oportunidades. Corroborando com essa compreensão, Gadotti (2007), no documento "O Mercosul Educacional e os Desafios do Século 21", assegura que é missão da Setor Educacional do Mercosul (SEM) promover um espaço educacional onde políticas educacionais promovam a integração do Mercosul, estimulem a mobilidade, intercâmbio e formação, com o objetivo de alcançar uma educação de qualidade para todos, com foco especial nos setores mais vulneráveis da sociedade, buscando a justiça social. Gadotti (2007) afirma que a grande oportunidade dos pobres está no acesso a uma educação de qualidade e reitera a questão da qualidade aliada à igualdade a responsabilidade social da instituição diz muito sobre sua qualidade.

Nessa categoria, o termo qualidade aparece associado à responsabilidade social das IES e equidade no âmbito da avaliação promovida pelo SINAES. A relevância social, por sua vez, se expressa na divulgação dos resultados das avaliações para a sociedade civil, ao Estado e à comunidade acadêmica como prestação de contas, sendo apresentadas, principalmente, sob a forma de indicadores de qualidade.

\section{Quando a qualidade é excelência}

Cunha e Pinto $(2009$, p. 572) ressaltam que os termos "qualidade" e "excelência" apontam para o máximo, para aquilo que é o melhor. Fávero (1998, p. 66) assinala que ex- 
celência e qualidade "são características mais que desejáveis na organização de instituições de educação superior e no trabalho por elas realizado". Nesse sentido, Cabrito (2009, p. 198) entende que uma avaliação a serviço da excelência é indispensável, contudo, o autor ressalta que essa "avaliação deve servir para que cada escola encontre o seu caminho e não para promover concorrência, rivalidade, discriminação, num claro processo de reprodução das exclusões e das desigualdades sociais". Para que isso ocorra, Perrenoud (1999, p. 10) defende que "passemos da medida obsessiva da excelência a uma observação formativa a serviço da regulação da regulação das aprendizagens".

$\mathrm{O}$ "Estudo Internacionalização, Gestão Democrática e Autonomia Universitário em Questão" (2005), organizado por Valdemar Sguissardi, Maria Estela Dal Pai Franco e Marília Costa Morosini apresenta uma série de textos que debatem os temas internacionalização, gestão democrática e autonomia universitária. Sguissardi, Franco e Morosini (2005) apontam que nos principais documentos dos organismos multilaterais (Fundo Monetário Internacional, Banco Mundial, Centro de Informação Bancária, Organização Mundial do Comércio) que financiam programas e projetos educacionais em países em desenvolvimento, o que realmente tem valor é que "a excelência acadêmica seja medida por critérios de qualidade nos moldes administrativo-empresariais (produto, custo/benefício)" (SGUISSARD; FRANCO; MOROSINI, 2005, p. 15). Os autores entendem que o padrão de qualidade está aos moldes de uma perspectiva gerencialista da educação, nos quais são elencados indicadores a serem seguidos pelas instituições.

Em outro momento do estudo "Internacionalização, gestão democrática e autonomia universitária em questão" o termo excelência é posto em discussão concernente à reforma da educação superior brasileira sendo que, para que as redes de pesquisa do ensino superior alcancem nível de excelência é preciso estabelecer parceria:

[...] com instituições/grupos nacionais e internacionais, fortalecendo as bases científicas e tecnológicas do País, o que poderia aumentar a participação na comunidade científica nacional e internacional, incrementar o potencial de negociação nos fóruns internacionais e ampliar a participação no mercado internacional, preservando os interesses nacionais, mediante a revitalização do Mercosul (SGUISSARD; FRANCO; MOROSINI, 2005, p. 48).

Ao tratar de mercado na educação superior, é discutida a autonomia institucional das IES, de maneira que esteja ligada à capacidade empreendedora de estabelecer critério de eficiência mais específico e flexível. Uma das lógicas econômicas está na eficiência dos mecanismos de avaliação do sistema universitário, para alcançar um mercado competitivo por resultados (SGUISSARD; FRANCO; MOROSINI, 2005).

Por sua vez, no documento "Avaliação externa de instituições de educação superior: diretrizes e instrumento" (2005b) o termo excelência é indicador de qualidade ligado à infraestrutura, à instalação, ao material didático-pedagógico, à biblioteca e ao laboratório. Não existe, no referido documento, uma explanação mais aprofundada de qualidade como expressão de excelência, o que se pode destacar é a busca que as IES têm em desenvolver processos avaliativos que gerem qualidade nos resultados alcançados. 
No documento "Sistema Nacional de Avaliação da Educação Superior SINAES: Bases para uma Nova proposta da Educação Superior" (BRASIL, 2003b), excelência refere-se às IES que obtiveram padrões internacionais ou se constituíram como centros de excelência. O documento menciona que na avaliação de cursos de pós-graduação realizada pela Coordenação de Aperfeiçoamento de Pessoal de Nível Superior (CAPES) são atribuídas notas que variam de 1 a 7, sendo que os cursos que recebem as notas 6 e 7 são considerados nível de excelência, "segundo os padrões internacionais da área" (BRASIL, 2003b, p. 49).

No "Manual do Enade" (2005) é mencionado o termo excelência, referindo-se ao $§ 10$ do artigo $5^{\circ}$ da Lei n. 10.861, que instituiu o SINAES. Destaca que os estudantes que obtivessem os melhores desempenhos, no ENADE, receberiam "estímulo, na forma de bolsa de estudos, ou auxílio específico, ou ainda alguma outra forma de distinção com objetivo similar, destinado a favorecer a excelência e a continuidade dos estudos, em nível de graduação ou de pós-graduação" (BRASIL, 2005c, p. 51).

Nessa categoria, o termo qualidade é tido, num primeiro instante, na perspectiva gerencialista da educação, em que são elencados indicadores a serem seguidos pelas IES. Em outro momento, a excelência é indicador de qualidade ligado à infraestrutura, à instalação, ao material didático-pedagógico, à biblioteca, aos padrões internacionais de instituição e à continuidade dos estudos para o bom resultado de desempenho de estudante.

\section{Qualidade ancorada em índices e indicadores}

Os indicadores e índices podem, segundo Brooke e Cunha (2011), ajudar no monitoramento, planejamento e pesquisa; informar escolas sobre a aprendizagem dos seus alunos; prover estratégias de formação continuada; informar ao público; alocar resultados; e certificar alunos e escolar. A respeito da elaboração e a implantação do SINAES, Rothen e Barreyro (2011, p. 22) apontam que, no final de 2008, "contrariando a expectativa de que o SINAES teria papel central na regulação, foram criados dois índices com esse fim: o Conceito Preliminar de Cursos (CPC) e o Índice Geral de Cursos (IGC)". Polidori (2009, p. 439) ressalta que esses novos indicadores inseridos no processo avaliativo, ferem, "e de forma severa, o Sistema de Avaliação que tem como finalidade ser processual, formativo, emancipatório e que busca a melhoria da qualidade da educação superior no Brasil".

Para a implantação do SINAES, ocorreram embates e impasses entre diversos atores sociais, entidades representativas da sociedade civil e Estado, entre eles, cabe destacar a atuação da CEA. Após a Comissão ter divulgado o documento "Sistema Nacional de Avaliação da Educação Superior SINAES: Bases para uma Nova proposta da Educação Superior" (BRASIL, 2003b) os veículos de comunicação reagiram com fortes embates, e mesmo dentro do próprio MEC, contra as alterações no Exame Nacional de Curso (ENC), popularmente chamado de Provão, conforme destacam os trabalhos de Rothen, David e Lopes (2008) e Barreyro e Rothen (2014). O ministro Cristovam Buarque elaborou uma proposta intermediária que utiliza instrumentos produzidos nos governos Fernando Henrique Cardoso e nas ideias propostas pelo documento do SINAES.

As ideias do então ministro Cristovam Buarque encontram-se no documento "Sistema 
Nacional de Avaliação e Progresso da Educação Superior: Uma nova sistemática de avaliação do Ensino Superior brasileiro" (BRASIL, 2003a), que trata da criação de um sistema de avaliação apoiado em quatro pilares: o processo de ensino, o processo de aprendizagem, a capacidade institucional e a responsabilidade do curso com a sociedade em geral. A avaliação se encerraria com a apresentação de um Relatório de Avaliação e Progresso, cuja principal consequência seria a "indução da melhoria da qualidade dos cursos superiores, em função do conhecimento do Índice, dos indicadores parciais, da classificação dos cursos e do Protocolo de Compromissos" (BRASIL, 2003a, p. 11, grifos do autor).

Ainda, nesse documento (BRASIL, 2003a, p. 7) é prevista a criação do Índice do Desenvolvimento do Ensino Superior (IDES), que, segundo o mesmo, seria um "salto de qualidade na avaliação realizada até aqui, e por isso será utilizado pelo MEC em suas análises, classificações e medidas regulatórias, que incluem o credenciamento e o descredenciamento de cursos e instituições". Para aferir a contribuição dos cursos das IES à sociedade, o documento indica a criação de um indicador específico a fim de verificar "os padrões de eficiência e eficácia do modelo de gestão dessas atividades, assim como, a democratização e efetiva participação da comunidade acadêmica na definição de propósitos e na administração da instituição" (BRASIL, 2003a, p. 6). Em decorrência disso, é editada a "Medida Provisória $n^{\circ} 147$ que Institui o Sistema Nacional de Avaliação e Progresso do Ensino Superior e dispõe sobre a avaliação do ensino superior" (BRASIL, 2003c). A Medida menciona em seu artigo 11 que cabe ao Ministério da Educação tornar público e disponível o resultado da avaliação dos cursos, e que esse resultado deveria ser reunido nos seguintes níveis: I - qualidade institucional satisfatória, II - qualidade institucional regular e III - qualidade institucional insatisfatória.

No documento "As diretrizes para Avaliação das Instituições de Educação" (BRASIL, 2004) é assinalada a importância da autoavaliação institucional como um indicador de melhoria da qualidade, sendo na maioria das vezes conduzida e sistematizada pela CPA. Isso porque são gerados indicadores de qualidade e, em decorrência disso, acontece a prestação de contas à sociedade civil do investimento recebido e, ademais, é verificável o nível de qualidade do ensino que é ofertado pelas IES. Para que a IES obtenha uma melhora da qualidade acadêmica, é importante o comprometimento dos gestores, da CPA e da comunidade com o desenvolvimento da avaliação institucional.

No documento "Avaliação Externa de Instituições de Educação Superior: diretrizes e instrumento" (BRASIL, 2005b), ao mencionar a avaliação externa do SINAES, há uma busca em extrair indicadores de qualidade de cada IES e do sistema como um todo (BRASIL, 2005b). Com base nesses indicadores há uma tentativa do Estado em instituir a cultura da qualidade para que, nos processos avaliativos, haja confiança na divulgação dos resultados, como forma da prestação de contas. Cabe ressaltar que a condição valorativa da qualidade varia de uma organização acadêmica para outra, isso porque cada IES tem autonomia para promover a sua qualidade acadêmica e como ela se manifestará nos resultados da avaliação do SINAES. Entretanto, há referências universais para verificar a qualidade nas diferentes organizações acadêmicas que são: "a adequação e a pertinência dos proces- 
sos de formação, o rigor acadêmico e científico, a condição social, científica e cultural da produção acadêmica, a construção da cidadania e o exercício da democracia" (BRASIL, 2005b, p. 11).

Fernandes et al. (2009), no documento "Avaliação de cursos na educação superior: a função e a mecânica do Conceito Preliminar de Curso" (CPC), analisam a contribuição do CPC como indicador que compõe o Sistema. Os autores explicam que, no âmbito do SINAES, insumos e processos são combinados para avaliar os indicadores de resultados e que, a partir desse momento, dentro do SINAES, haveria outra medida para orientar a qualidade do ensino oferecido aos estudantes, o CPC. "Obtido pela combinação de indicadores de qualidade já existentes, o CPC tem a função de orientar e racionalizar as avaliações in loco" (FERNANDES et al., 2009, p. 8).

Os autores asseveram que o CPC tem papel fundamental no SINAES, pois caso a nota do curso obtida no CPC for maior que 2 pode ser dispensada a visita in loco e assim "o CPC torna-se automaticamente o Conceito de Curso". No caso dos cursos visitados, "o Conceito de Curso é dado pelos avaliadores, mas, caso divirja do CPC, é necessária uma justificação sólida dos motivos" (FERNANDES et al., 2009, p. 8). Essa é uma tentativa de eliminar as contradições entre os indicadores objetivos e os indicadores da avaliação in loco. Dessa forma, o CPC torna-se "um indicador intermediário que viabiliza e dá consistência ao Conceito de Curso" (FERNANDES et al., 2009, p. 8) e incita "maior coerência entre as avaliações in loco e os indicadores de qualidade" já que "os resultados mostram que o CPC se aproxima muito do que denominamos indicador 'ideal'" (FERNANDES et al., 2009, p. 17).

No documento "Manual dos Indicadores de Qualidade" (2011, p. 5) está expresso que os indicadores "são medidas da qualidade dos cursos e das instituições do país”. Nesse manual, o CPC é apontado como um dos indicadores de qualidade, sendo contemplado por meio de notas, que indicam "medidas relativas à qualidade do curso" (BRASIL, 2011, p. 5). Esses componentes englobam informações a respeito da infraestrutura, recursos didático-pedagógicos, corpo docentes (Professores Doutores; Professores Mestres; Professores com Regime de Dedicação Integral ou Parcial), o desempenho obtido pelos estudantes concluintes no ENADE e os resultados do Indicador de Diferença entre os Desempenhos Observado e Esperado (IDD) (BRASIL, 2011).

Outros documentos publicados posteriormente retomam essas discussões, caso da "Nota Técnica n 029", que define o cálculo do CPC referente ao ano de 2011 (BRASIL, 2012a), da "Portaria n 386", que reafirma o ENADE, o CPC e o Índice Geral de Cursos Avaliados da Instituição (IGC) como indicadores da educação superior e aponta as fontes para cálculo do ano de 2011 (BRASIL, 2012b) e do "Despacho da Secretária da Secretaria de Regulação e Supervisão da Educação Superior (SERES)” (BRASIL, 2012c), que também trata do CPC como indicador de qualidade para os cursos.

No "Despacho do Secretário da Seres" (BRASIL, 2013) é tornado público os critérios para a revisão da medida imposta pelo despacho anterior (BRASIL, 2012c) relativo aos cursos que obtiveram resultados insatisfatórios nos CPC's referentes aos anos 2008 e 2011, mas que, por sua vez, apresentaram tendência de melhora em seus indicadores contínuos. Nesse 
caso, define-se que "não poderão ser revistas às medidas cautelares impostas às IES cujos cursos estejam submetidos a processos de supervisão ativos, nos quais existe penalidade ou medida cautelar já aplicada" e "também não poderão ser revistas às medidas cautelares impostas às IES cujos cursos tenham obtido resultado insatisfatório, em qualquer das dimensões, no último CC - Conceito de Curso calculado pelo INEP" (BRASIL, 2013, p. 122).

Nessa categoria, o termo qualidade está associado à criação dos indicadores de qualidade surgidos ao longo do período de implantação do SINAES. Isso pode ser evidenciado com o CPC, que utiliza na sua formulação dados da infraestrutura, recursos didático-pedagógicos, corpo docente, além do desempenho dos estudantes que prestaram o ENADE e os resultados do IDD; e o IGC, que avalia as IES considerando a média dos CPCs, a média dos conceitos de avaliação atribuídos pela CAPES e a distribuição dos estudantes entre os níveis de ensino.

\section{CONSIDERAÇões FINAIS}

O artigo teve por objetivo identificar o conceito de qualidade na educação superior presente nos documentos oficiais e nos dispositivos legais elaborados no Brasil no período de 2003 a 2013. Cabe destacar que as concepções de qualidade variaram ao longo do tempo, pois, inicialmente o termo qualidade aparece associado a uma qualidade formativa-educativa que possibilita desvelar a realidade institucional por meio da produção de valores e de sentidos para os envolvidos num sistema global e integrador, sendo em seguida adotada uma visão de qualidade gerencialista voltada para eficiência, eficácia e produtividade, em que práticas regulatórias foram ganhando força e espaço, a ponto de apenas uma dos eixos avaliativos do SINAES determinar a qualidade ofertada pelas IES.

Nos primeiros anos de implantação do SINAES (2003-2004), quando os documentos abrangem o período da regulamentação a implementação do sistema, nota-se uma perspectiva de qualidade que aponta para uma visão formativa-educativa. Nesse período, a ênfase se encontra na melhoria da qualidade e na responsabilidade social, abrangendo a IES de forma global e integradora. O alcance da qualidade perpassa, portanto, desde questões político-sociais, como a expansão de oportunidades educacionais, até a aferição da aprendizagem dos alunos, sua formação para a cidadania e para o mundo do trabalho, entendendo-se, assim, que uma avaliação educativa deve ser "uma produção de sentidos sobre o cumprimento, pelos sistemas e pelas instituições, das finalidades de formação de cidadãos, aprofundamento dos valores democráticos da vida social, e elevação material e espiritual da sociedade" (DIAS SOBRINHO, 2008a, p. 193).

Posteriormente, no movimento de desenvolvimento e consolidação do SINAES (2005-2013) o termo qualidade passou a assumir cada vez mais a ideia de instrumentos, roteiros e diretrizes, sobretudo a partir do Decreto 5.773 de 2006, quando a qualidade surge numa perspectiva gerencialista e distancia-se de sua formulação inicial que propunha uma visão de qualidade formativa-educativa. Isso pode ser encontrado de modo mais claro e direto nos documentos que normatizam a criação dos índices e indicadores, caso do CPC e do 
IGC, e na ênfase da excelência como um indicador da qualidade. Em razão dessas medidas "o SINAES, ainda em processo de consolidar-se como cultura, pouco a pouco foi perdendo sua riqueza teórica e sua potencialidade ético-política e foi se reduzindo a ÍNDICES" (DIAS SOBRINHO, 2008b, p. 820).

Barreyro e Rothen (2014), analisando a política de avaliação da educação superior desenvolvida durante os governos de Luiz Inácio Lula da Silva (2003-2010), corroboram com a afirmação anterior, na medida em que os autores concluem que o SINAES tentou empreender uma mudança na lógica da avaliação instituída desde o Provão no governo Fernando Henrique Cardoso (1995-2003). Contudo, os autores ressaltam que "em sua implantação, o SINAES sofreu profundas transformações a partir da criação do Conceito Preliminar de Cursos (CPC) e do Índice Geral de Cursos (IGC), que foram incorporados ao final do segundo Governo Lula" (BARREYRO; ROTHEN, 2014, p. 61), assim, "a avaliação formativa é 'des-induzida', ao privilegiar os resultados do ENADE sobre os outros" (ROTHEN; BARREYRO, 2011, p. 31).

As avaliações se justificam pela busca da melhoria da qualidade rumo à excelência da educação superior, contudo essa é uma interpretação particular. Nos documentos analisados, não é encontrada essa afirmação, inclusive, em um dos únicos momentos em que é mencionado o termo excelência, esse veio referenciar a grande dificuldade em um curso conseguir a excelência, visto que um pequeno detalhe em que a instituição não atinja a nota máxima nas avaliações pode comprometer esse diagnóstico.

Ao findar este texto, nota-se que ele contribui no campo educacional ao fomentar discussões e reflexões sobre o conceito de qualidade presente nos documentos oficiais e dispositivos legais. Conclui-se que os resultados obtidos das avaliações podem promover a qualidade gerencialista ou formativa-educativa, bem como, as duas concomitantemente, visto que, apesar de haver diferenças entre elas, possuem uma proximidade, que é exibir ao final do processo a melhoria daquilo que foi avaliado. Importante ressaltar ainda que a discussão acerca da qualidade da educação superior não deve ficar restrita aos documentos e pesquisadores, mas deve transpor os limites teóricos e chegar às instituições, aos professores e envolvidos com a educação, pois, a qualidade da educação possui diversas faces que merecem ser compreendidas e exploradas para os benefícios a todos.

\section{REFERÊNCIAS}

BALZAN, Newton Cesar; DIAS SOBRINHO, José Dias. Introdução. In: (Orgs.). Avaliação Institucional: teoria e experiências. São Paulo: Cortez, 1995, p. 7-9.

BARREYRO, Gladys Beatriz. Mapa do Ensino Superior Privado. Brasília: INEP, 2008.

BARREYRO, Gladys Beatriz; ROTHEN, José Carlos. Para uma história da avaliação educação da superior brasileira: análise dos documentos do PARU, CNRES, GERES e 
PAIUB. Avaliação, Campinas; Sorocaba, v. 13, n. 1, p. 131-152, mar. 2008. Disponível em: $<$ http://periodicos.uniso.br/ojs/index.php?journal=avaliacao\&page $=$ article\&op=view \&path[] $=256>$. Acesso em: 15 abr. 2015.

BARREYRO, Gladys Beatriz; ROTHEN, José Carlos. Percurso da avaliação da educação superior nos Governos Lula. Educ. Pesqui., São Paulo, v. 40, n. 1, p. 61-76, jan./mar. 2014. Disponível em: <http://www.revistas.usp.br/ep/article/view/81861>. Acesso em: 14 abr. 2015.

BARREYRO, Gladys Beatriz; ROTHEN, José Carlos. "SINAES" contraditórios: considerações sobre a elaboração e implantação do sistema nacional de avaliação da educação superior. Educ. Soc., Campinas, v. 27, n. 96 - Especial, p. 955-977, out. 2006. Disponível em: $<$ http://www.scielo.br/scielo.php?script=sci_arttext\&pid=S0101-73302006000300015\&ln $\mathrm{g}=\mathrm{en} \& \mathrm{nrm}=$ iso\&tlng=pt $>$. Acesso em: 15 abr. 2015.

BELLONI, Isaura. Avaliação Institucional: um instrumento de democratização da educação. Linhas Críticas, Brasília, v. 5, n. 9, p. 31-58, jul./dez. 1999. Disponível em: <http:// periodicos.unb.br/index.php/linhascriticas/article/view/6711>. Acesso em: 16 out. 2015.

BRASIL. Constituição da República Federativa do Brasil. Brasília: Senado Federal: Centro Gráfico, 1988.

BRASIL. Sistema Nacional de Avaliação e Progresso da Educação Superior: Uma nova sistemática de avaliação do Ensino Superior brasileiro. Brasília: MEC, 2003a.

BRASIL. Instituto Nacional de Estudos e Pesquisas Educacionais Anísio Teixeira (INEP). SINAES - Sistema Nacional de Avaliação da Educação Superior: bases para uma nova proposta de avaliação da educação superior brasileira. Brasília: INEP, 2003b.

BRASIL. Medida Provisória no ${ }^{\circ}$ 147, de 15 de dezembro de 2003. Institui o Sistema Nacional de Avaliação e Progresso do Ensino Superior e dispõe sobre a avaliação do ensino superior. Diário Oficial da União República Federativa do Brasil. Brasília, 16 dez. 2003c.

BRASIL. Lei $n^{\circ}$. 10.861, de 14 de abril de 2004. Institui o Sistema Nacional de Avaliação da Educação Superior (SINAES) e dá outras providências. Diário Oficial da União, Brasília, 15 abr. 2004a.

BRASIL. Ministério da Educação. Instituto Nacional de Estudos e Pesquisas Educacionais Anísio Teixeira (INEP). Comissão Nacional de Avaliação da Educação Superior (CONAES). Diretrizes para a avaliação das instituições de educação superior. Brasília: MEC/ CONAES/ INEP, 2004b. 
BRASIL. Ministério da Educação. Instituto Nacional de Estudos e Pesquisas Educacionais Anísio Teixeira (INEP). Comissão Nacional de Avaliação da Educação Superior (CONAES). Sistema Nacional de Avaliação da Educação Superior - SINAES: Roteiro de auto-avaliação institucional. Brasília: MEC/CONAES/SESU/ INEP, 2004c.

BRASIL. Ministério da Educação. O desenvolvimento da educação. Educação de qualidade para todos os jovens: desafios, tendências e prioridades. Brasília: MEC, 2004d.

BRASIL, Ministério da Educação. Instituto Nacional de Estudos e Pesquisas Educacionais Anísio Teixeira (INEP). Portaria n. 31, de 17 de fevereiro de 2005. Diário Oficial da União República Federativa do Brasil. Brasília, n. 34, 21 fev. 2005a, seção 1, p. 15.

BRASIL, Ministério da Educação. Comissão Nacional de Avaliação da Educação Superior (CONAES). Instituto Nacional de Estudos e Pesquisas Educacionais Anísio Teixeira. Avaliação externa de instituições de educação superior: diretrizes e instrumento. Brasília, 2005b, 175 p.

BRASIL, Ministério da Educação. Instituto Nacional de Estudos e Pesquisas Educacionais Anísio Teixeira. Manual do Exame Nacional de Desempenho dos Estudantes ENADE 2006. Brasília, 2005c. 72 p.

BRASIL. Ministério da Educação. Comissão Nacional de Avaliação da Educação Superior (CONAES). Instituto Nacional de Estudos e Pesquisas Educacionais Anísio Teixeira (INEP). Avaliação de cursos de graduação: instrumento. Brasília, 2006, 180 p.

BRASIL. Manual do Enade 2009: revista e atualizada. Brasília: 2009, 79 p.

BRASIL. Instituto Nacional de Estudos e Pesquisas Educacionais Anísio Teixeira. Manual dos Indicadores de Qualidade. Brasília: INEP, 2011.

BRASIL. Instituto Nacional de Estudos e Pesquisas Educacionais Anísio Teixeira. Nota Técnica n ${ }^{\circ}$. 029, de 15 de outubro de 2012. Diário Oficial da União República Federativa do Brasil. Brasília: INEP, 2012a.

BRASIL. Instituto Nacional de Estudos e Pesquisas Educacionais Anísio Teixeira. Portaria n. 386, de 17 de outubro de 2012. Diário Oficial da União República Federativa do Brasil. Brasília: INEP, 2012 b.

BRASIL. Secretaria de Regulação e Supervisão da Educação Superior. Despacho da Secretária, de 3 de dezembro de 2012. Diário Oficial da União República Federativa do Brasil. Brasília: DIREG/SERES/MEC, 2012c. 
BRASIL. Secretaria de Regulação e Supervisão da Educação Superior. Despacho do Secretário, de 2 de janeiro de 2013. Diário Oficial da União República Federativa do Brasil. Brasília: SERES/MEC, 2013.

BROOKE, Nigel; CUNHA, Maria Amália A. A avaliação externa como instrumento da gestão educacional nos estados. São Paulo: Fundação Vitor Civita, 2011. Disponível em: <http://www.institutounibanco.org.br/wp-content/uploads/2013/07/avaliacao_externa. pdf. $>$ Acesso em: 16 out. 2015.

CABRITO, Belmiro Gil. Avaliar a qualidade em educação: avaliar o quê? Avaliar como? Avaliar para quê? Cad. Cedes, Campinas, v. 29, n. 78, p. 178-200, ago. 2009. Disponível em: $<$ http://www.scielo.br/scielo.php?script=sci_arttext\&pid=S0101-32622009000200003\&ln $\mathrm{g}=\mathrm{pt} \& \mathrm{nrm}=\mathrm{iso} \& \mathrm{t} \operatorname{lng}=\mathrm{pt}>$. Acesso em: 17 out. 2015.

CHIZZOTTI, Antonio. Pesquisa Qualitativa em Ciências Humanas e Sociais. Petrópolis: Vozes, 2006.

COLIGAÇÃO LULA PRESIDENTE. Programa de Governo 2002. São Paulo: Comitê Lula Presidente, 2002.

CUNHA, Maria Isabel da; PINTO, Marialva Moog. Qualidade e educação superior no Brasil e o desafio da inclusão social na perspectiva epistemológica e ética. R. bras. Est. pedag., Brasília, v. 90, n. 226, p. 571-591, set./dez. 2009. Disponível em: <http://rbep.inep. gov.br/index.php/RBEP/article/view/1551>. Acesso em: 17 out. 2015.

DEMO, Pedro. Avaliação qualitativa. Campinas: Autores Associados, 2005.

DEMO, Pedro. Ciências sociais e qualidade. São Paulo: ALMED, 1985.

DIAS SOBRINHO, José. Avaliação ética e política em função da educação como direito público ou como mercadoria? Educ. Soc., Campinas, vol. 25, n. 88, p. 703-725, Especial - Out. 2004. Disponível em: <http://www.scielo.br/pdf/es/v25n88/a04v2588.pdf>. Acesso em: 14 jun. 2017.

DIAS SOBRINHO, José. Avaliação educativa: produção de sentidos com valor de formação. Avaliação, Campinas; Sorocaba, v. 13, n. 1, p. 193-207, mar. 2008a. Disponível em: $<$ http://periodicos.uniso.br/ojs/index.php?journal=avaliacao\&page=article\&op=view\&pa th[] $=259>$. Acesso em: 16 out. 2015.

DIAS SOBRINHO, José. Qualidade, avaliação: do Sinaes a índices. Avaliação, Campinas; Sorocaba, v. 13, n. 3, p. 817-825, nov. 2008b. Disponível em: <http://periodicos.uniso. 
br/ojs/index.php?journal=avaliacao\&page=article\&op=view\&path[] $=284 \&$ path[] $=285>$. Acesso em: 17 out. 2015.

DIAS SOBRINHO, José. Avaliação e transformações da educação superior brasileira (1995-2009): do Provão ao Sinaes. Avaliação, Campinas; Sorocaba, v. 15, n. 1, p. 195-224, mar. 2010a. Disponível em: <http://www.scielo.br/scielo.php?pid=S1414$-40772010000100011 \&$ script $=$ sci_abstract\&tlng=pt $>$. Acesso em: 13 abr. 2015.

DIAS SOBRINHO, José. Democratização, qualidade e crise da educação superior: faces da exclusão e limites da inclusão. Educ. Soc., Campinas, v. 31, n. 113, p. 1.223-1.245, dez. 2010b. Disponível em: <http://www.scielo.br/scielo.php?script=sci_arttext\&pid $=$ S0101-73302010000400010>. Acesso em: 16 out. 2015 .

DOURADO, Luiz Fernandes; OLIVEIRA, João Ferreira de; SANTOS, Catarina de Almeida. A qualidade da educação: conceitos e definições. Série Documental: Textos para Discussão. Brasília, v. 24, n. 22, p. 5-34, 2007.

FÁVERO, Maria de Lourdes A. A dimensão histórico-política da nova Lei de Diretrizes e Bases e a Educação Superior. In: CATANI, Afrânio Mendes (Org.). Novas perspectivas de educação superior na América Latina no Limiar do Século XXI. Campinas: Autores Associados, 1998, p. 55-73.

FERNANDES, Reynaldo et al. Avaliação de cursos na educação superior: a função e a mecânica do Conceito Preliminar de Curso. Série Documental: Textos para Discussão. Brasília, v. 32, 2009.

FREITAS, Luiz Carlos de. Qualidade negociada: avaliação e contra-regulação na escola pública. Educ. Soc., Campinas, v. 26, n. 92, p. 911-933, Especial - Out. 2005. Disponível em: <http://repositorio.unicamp.br/jspui/bitstream/REPOSIP/24504/1/S010173302005000300010.pdf $>$. Acesso em: 10 jun. 2017.

FREITAS, Luiz Carlos de. Prefácio. In: SORDI, Mara Regina Lemes de; SOUZA, Eliana da Silva. A avaliação institucional como instância mediadora da qualidade da escola pública: a Rede Municipal de Campinas como espaço de aprendizagem. Campinas: Millennium Editora, 2009, p. V-VII.

GADOTTI, Moacir. O Mercosul Educacional e os desafios do século 21. Série Documental: Textos para Discussão. Brasília, v. 25, n. 22, 2007.

GOMEZ, Gregório R.; FLORES, Javier; JIMÉNEZ, Eduardo. Metodologia de la Investigacion Cualitativa. Malaga, España: Ediciones Aljibe, 1996. 
INEP. O desafio de uma educação de qualidade para todos: educação no Brasil - 19902000. Brasília: INEP, 2004b.

INEP. Relatório de Gestão 2003. Brasília: INEP, 2004a.

LÜDKE, Menga; ANDRÉ, Marli E. D. A. Pesquisa em Educação: abordagens qualitativas. São Paulo: EPU, 1986.

OLIVEIRA, Romualdo Portela. O Direito à Educação na Constituição Federal de 1988 e seu restabelecimento pelo sistema de justiça. Rev. Bras. Educ., Rio de Janeiro, v. 11, p. 61-74, mai./ago.1999. Disponível em: <http://egov.ufsc.br/portal/sites/default/files/ anexos/30315-31270-1-PB.pdf>. Acesso em: 17 out. 2015.

PERRENOUD, Philippe. Introdução. In: - Avaliação: da excelência à regulação das aprendizagens - entre duas lógicas. Trad. Patrícia Chittoni Ramos. Porto Alegre: Artes Médicas Sul, 1999, p. 9-18.

POLIDORI, Marlis Morosini. Políticas de avaliação da Educação Superior brasileira: Provão, Sinaes, IDD, CPC, IGC e... outros Índices. Avaliação, Campinas, v. 14, n. 2, p. 439452, jul. 2009. Disponível em: <http://periodicos.uniso.br/ojs/index.php?journal=avaliaca o\&page $=$ article\&op=view\&path[] $=314>$. Acesso em: 16 out. 2015.

RISTOFF, Dilvo; JUNIOR ALMEIDA, Vicente de Paula (Org.). Avaliação participativa: perspectivas e desafios. Brasília: INEP, 2005, 240 p.

ROTHEN, José Carlos; BARREYRO, Gladys Beatriz. Avaliação, agências e especialistas: padrões oficiais de qualidade da educação superior. Ensaio: aval. pol. públ. Educ., Rio de Janeiro, v. 17, n. 65, p. 729-752, out./dez. 2009. Disponível em: <http://www.scielo.br/pdf/ ensaio/v17n65/v17n65a10.pdf.>. Aceso em: 14 jun. 2017.

ROTHEN, José Carlos; BARREYRO, Gladys Beatriz. Avaliação da educação superior no segundo governo Lula: "Provão II" ou a reedição de velhas práticas? Educ. Soc., Campinas, v. 32, n. 114, p. 21-38, jan./mar. 2011. Disponível em: <http://www.scielo.br/scielo. php?script=sci_arttext\&pid=S0101-73302011000100002>. Acesso em: 14 abr. 2015.

ROTHEN, José Carlos; DAVID, Luciano; LOPES, Luciana Martins. Provão e ENADE em debate no JC E-mail: 2002 a 2006. Revista de Educação PUC-Campinas, Campinas, n. 25, p. 111-123, nov. 2008. Disponível em: <http://periodicos.puc-campinas.edu.br/seer/ index.php/reveducacao/article/view/99>. Acesso em: 13 abr. 2015.

SGUISSARDI, Waldemar; FRANCO, Maria Estela Dal Pai; MOROSINI, Marilia Costa (Org.). Internacionalização, gestão democrática e autonomia universitária em questão. Brasília: INEP, 2005, p. 54. 
SILVA JÚNIOR, João dos Reis; SGUISSARDI, Waldemar. O impacto da mercantilização da educação superior. Adusp, Ribeirão Preto, n. 19, p. 43-53, mar. 2000. Disponível em:

$<$ https://www.adusp.org.br/files/revistas/19/r19a09.pdf $>$. Acesso em: 12 fev. 2018.

TAVARES, Maria das Graças Medeiros et al. Políticas de expansão da educação superior no Brasil pós-ldb/96 - desafios para a avaliação. Inter-Ação, Goiânia, v. 36, n. 1, p. 81-99, jan./jun. 2011. Disponível em: $<$ https://www.revistas.ufg.br/interacao/article/view/15029>. Acesso em: 12 fev. 2018.

\section{Dados dos AUTORES:}

\section{José Carlos Rothen}

Pós-Doutor pela Université de Strasbourg (França). Doutor em Educação pela Universidade Metodista de Piracicaba. Professor do Programa de Pós-Graduação em Educação da Universidade Federal de São Carlos. São Carlos/ SP - Brasil. jcr3219@yahoo.com.br

\section{Regilson Maciel Borges}

Pós-Doutor em Educação pela Universidade Estadual de Ponta Grossa. Doutor em Educação pela Universidade Federal de São Carlos. Professor do Departamento de Educação da Universidade Federal de Lavras. Lavras/MG - Brasil. regilsonborges@gmail.com

\section{Andreliza Cristina de Souza}

Doutora em Educação pela Universidade Federal de São Carlos. Professora colaboradora da Universidade Estadual do Oeste do Paraná. Cascavel/PR - Brasil. andrelizacsouza@ gmail.com

\section{Joelma dos Santos Bernardes}

Pós-Doutora em Educação pela Universidade Estadual Paulista "Júlio de Mesquita Filho". Doutora em Educação na Universidade Federal de São Carlos. Mediadora de Ensino na Universidade Virtual do Estado de São Paulo. Araraquara/SP - Brasil. joelma.santos833@, gmail.com

\section{Pamela Cristina Botiglieri}

Mestranda em Educação na Universidade Federal de São Carlos. São Carlos/ SP - Brasil. pam_botiglieri@hotmail.com

Submetido em: 14-6-2017

Aceito em: 20-2-2019 